уДК 332.334

\title{
РАЗРАБОТКА ПРОГНОЗНОЙ МОДЕЛИ ТРАНСФОРМАЦИИ ЗЕМЕЛЬНЫХ УГОДИЙ ВЬЕТНАМА
}

\author{
Ковязин Василий Федорович', \\ vfkedr@mail.ru \\ Нгуен Тхи Суан', \\ ntxuandc81@gmail.com \\ ${ }^{1}$ Санкт-Петербургский горный университет,
Россия, 199106, г. Санкт-Петербург, Васильевский остров, 21 линия, 2.
}

Актуальность исследования. Вьетнам - аграрная страна, в настоящее время его развитие идет по пути индустриализации, но правительство по-прежнему озабочено количественными и качественными показателями сельскохозяйственных угодий. Поэтому прогнозирование ресурсного потенциала разных видов земельных угодий Вьетнама играет ключевую роль в управлении земельными ресурсами страны. Исследования ресурсного потенциала земель проведены на примере административной области Тиенхая, которая является прибрежным регионом страны, где преобладает сельскохозяйственный сектор экономики и характерны многие виды земельных угодий.

Цель: оценка пригодности земель разных угодий для прогноза использования их в будущем.

объектом исследования являются земельные угодья государственной собственности района Тиенхая социалистической республики Вьетнам.

Методы: методы эмпирического уровня: описание, наблюдение, измерение, сравнение, анкетный опрос, обобщение и моделирование. Для выявления динамики площадей земель различных категорий использовались космические снимки, а для их обработки - ГИС-технологии. При оценке пригодности земель к различным видам землепользований применялись методы ФАО (продовольственная и сельскохозяйственная организация ООН) и экспертных оценок. Важность факторов трансформации земель для разных видов их пользования рассчитана по методу аналитической иерархической процедуры Саати. Для разработки прогнозной модели трансформации земельных угодий во Вьетнаме выбраны цепи Маркова и современные компьютерные программы и технологии

Результаты. На основе дешифрирования космоснимков территории и ГИС-технологий построена матрица вероятности трансформации земельных угодий в Тиенхае с 2005 по 2015 гг. Нормированный вектор относительной важности факторов трансформации при оценке ресурсного потенциала земель для разных видов использования по методу аналитической иерархической процедуры Саати сформирован с помощью экспертов. Разработаны карты пригодности земель для различных типов земельных угодий. Создана модель прогноза земельных угодий в районе Тиенхая к 2025 г. По модели спрогнозированы площади землепользований в районе исследований через 10 лет.

\section{Ключевые слова:}

Земельные угодья, матрица трансформации, прогнозная модель, цепи Маркова, пригодность земли.

\section{Введение}

Земельные угодья - земельные участки планомерно и систематически используемые для различных целей. От вида земельных угодий зависит распределение доходов в стране. На вид пользования угодий оказывает влияние большое количество факторов. Для прогнозирования тенденции использования земель необходима вероятностная информация о землепользованиях и оценке уровня их ресурсного потенциала. В настоящее время для моделирования прогноза земельных угодий применяют известные программы (ArcGis и Idrisi Selva) и карты пригодности земель. Эти карты несут информацию о вероятности динамики вида земельных угодий в зависимости от природных условий и экономической ситуации в стране, плодородия и уровня ресурсного потенциала земли. Но учесть сложные связи между природными и экономическими показателями территории трудно, поэтому задача построения карт пригодности земель Тиенхая пока не решена. Мы попытались решить эту проблему.

\section{Методика исследования}

Для разработки прогнозной модели земельных угодий в районе Тиенхая использовались космические снимки, а прогнозирование включало несколько этапов исследований.

На первол этапе прогнозирования использовались космические снимки области Тиенхая 2005 г. и карты землепользований 2015 г. Далее с помощью ГИС-технологий разработаны карты землепользований и определена их динамики за период с 2005 по 2015 гг. [1-4].

На втором этапе разработаны карты пригодности земель для каждого типа землепользований. Пригодность земель определена с учетом экологических потребностей разных видов землепользований, их экономической эффективности и устойчивости внешней среды [5]. Кроме того, по земельному законодательству Вьетнама приоритетом развития являются земли сельскохозяйственного назначения [6]. Для оценки пригодности земель к ведению сельского хозяйства (выращивание риса, сельскохозяйственных культур, а также для рыбо- 
водства) использованы агрохимические свойства почвы. К этим свойствам отнесены: тип почвы, её гранулометрический состав, содержание гумуса, емкость катионного обмена, степень насыщенности основаниями, содержание растворенных солей в почве, $\mathrm{pH}_{\mathrm{kcl}}$, уровень увлажнения почвы, глубинно-глеевой слой, уровень загрязнения почвы оксидом алюминия [5, 7-10]. В качестве экономических факторов использованы: плотность населения, экономическая эффективность сельскохозяйственного производства, система орошения полей, расстояние до магистральных путей транспорта [11-14]. А для земель жилищного и специального назначения включали факторы: плотность населения, уровень развития экономики коммун, расстояние до магистральных путей транспорта, расстояние до важных экономических, общественных, рекреационных объектов и критерии приоритета сельского хозяйства, которые зависят от пригодности земель для сельскохозяйственных культур, рисовых полей, для рыбоводства и неиспользуемые. Установлено, что развитие земель жилищного и специального назначения влияет на качество земель для сельскохозяйственных культур, рисовых полей и рыбоводства [15-19]. В частности, участки сельскохозяйственного назначения имеют высокую ценность, поэтому их перевод в другие категории земель затруднен. Неиспользуемые земли государство, наоборот, призывает переводить в другие категории пользования.

Ресурсный потенциал территории Тиенхая оценивался по методике ФАО. При этом использовались следующие 4 класса оценки земель:

- $\mathrm{S} 1$ - высокая пригодность (70-100 баллов);

- $\mathrm{S} 2$ - средняя пригодность (50-70 баллов);

- $\mathrm{S} 3$ - ограниченная пригодность (15-50 баллов);

- $\mathrm{N}$ - временно непригодные земли (0-15 баллов).

На основе метода рейтинговой оценки ФАО и стандарта оценки сельскохозяйственных земель и для планирования земельных угодий различных видов нами для Министерства сельского хозяйства и развития сельских районов Вьетнама сформированы критерии и проведена оценка пригодности земель с учетом различных факторов (Si).

Ранжирование факторов трансформации земель по их важности проведено нами при помощи весовых коэффициентов. Весовые коэффициенты в нашем исследовании получены с помощью экспертов. В качестве тридцати восьми экспертов привлекались известные в социалистической республике Вьетнам ученые и специалисты органов управления земельными ресурсами. Эксперты подобраны по критериям метода аналитической иерархической процедуры Саати.

Эксперты оценивали значимость факторов по методике американского математика Томаса $\mathrm{Ca}$ ати, который попарно сравнивал альтернативы [20]. Фиксация результатов сравнения пары альтернатив проводилась по шкале следующего типа: - 1 - равноценность;

- 3 - умеренное превосходство;
- 5 - сильное превосходство;

- 7 - очень сильное превосходство;

- 9 - высшее (крайнее) превосходство.

Мы имеем n-факторов трансформации земель $F_{1} \ldots, F_{n}$ и вектор относительных весов оценки этих факторов $w\left(w_{1}, \ldots w_{n}\right)$ по степени их влияния на уровень ресурсного потенциала для разных видов хозяйственного использования земель. При этом должно выполняться равенство (1):

$$
\sum_{i=n}^{n} w i=1 .
$$

Сравнивая попарно степень влияния факторов по весам, получаем отношение влияния их в виде квадратной матрицы $F_{n}$ такого порядка (табл. 1$)$.

Таблица 1. Квадратная матрица

Table 1. Square matrix

\begin{tabular}{|c|c|c|c|c|c|c|}
\hline$F$ & $F 1$ & $F 2$ & $\ldots$ & $\ldots$ & $\ldots$ & $F n$ \\
\hline$F 2$ & $w_{1} / w_{1}$ & $w_{1} / w_{2}$ & $\ldots$ & $\ldots$ & $\ldots$ & $w_{1} / w_{n}$ \\
\hline$\ldots$ & $w_{2} / w_{1}$ & $w_{2} / w_{2}$ & $\ldots$ & $\ldots$ & $\ldots$ & $w_{2} / w_{n}$ \\
\hline$\ldots$ & $\ldots$ & $\ldots$ & $\ldots$ & $\ldots$ & $\ldots$ & $\ldots$ \\
\hline$F n$ & $w_{n} / w_{1}$ & $\ldots$ & $\ldots$ & $\ldots$ & $\ldots$ & $w_{n} / w_{n}$ \\
\hline
\end{tabular}

Элементы матрицы имеют такие свойства $(2)-(4)$

$$
\begin{gathered}
f_{i j}=w_{i} / w_{j}, \\
f_{\mathrm{ij}}=1 / f_{\mathrm{ji}} \\
f_{i j} \times f_{j k}=f_{i k} .
\end{gathered}
$$

В условиях нечеткой исходной информации вектор весов w является неизвестным. Его находим с помощью свойства матрицы $F$ при решении уравнения 9 (5):

$$
(F-n \times I) w=0,
$$

где $I$ - единичная матрица.

Вначале находили нормированный вектор матрицы, что соответствует максимальному собственному числу, путем решения выражения (4), (5). Сравнивая факторы трансформации землепользований по степени их значимости, на уровень ресурсного потенциала земель для разных видов хозяйственного использования, получали матрицы парных сравнений суждений экспертов. Основой для оценки уровня ресурсного потенциала района Тиенхая для разных видов использования земель послужил интегральный показатель уровня ресурсного потенциала, который обозначен через $Y$ и рассчитан по формуле (6)

$$
Y=\sum_{(i=1)}^{n} W i \times S i,
$$

где $W i$ - коэффициент относительной значимости (вес) фактора трансформаций земель; $\mathrm{Si}$ - оценка пригодности земель фактора трансформаций земель, в баллах.

На третьем этапе разработана модель прогнозирования земельных угодий на ближайшее десятилетие. В настоящее время одним из наиболее эф- 
фективных и широко используемых способов моделирования изменений земельных угодий, учитывающих пространственное взаимодействие между элементами подобного изображения, является применение клеточных автоматов (КА) [21]. Один из наиболее перспективных и рациональных способов моделирования изменений земельных угодий основан на использовании статистического аппарата Марковских цепей. В этом случае информация об изменениях земельных угодий содержится в матрице вероятностей переходов $P=[p i j]$, каждый элемент которой является вероятностью перехода вида земельных угодий $\omega i$ в тип $\omega j$, где $i, j=1, \ldots, m, m$ - число типов земельных угодий на изучаемой территории, выявленное на этапе исследования (табл. 2) [21-24]. В настоящее время моделирование прогноза земельных угодий с помощью Марковских цепей [23] широко используется для разработки карт пригодности земельных угодий для различных видов использований.

\section{Обсуждение результатов}

По результатам исследований нами разработана матрица трансформации земельных угодий на 10 лет, в которой отображена динамика площадей каждого вида земельных угодий (табл. 2) [25-27].
Таблица 2. Матрица вероятности трансформации земельных угодий в районе Тиенхая с 2005 по 2015 г2., \% (P)

Table 2. Matrix of land transformation probability in Tienhai from 2005 to 2015 , \% (P)

\begin{tabular}{|c|c|c|c|c|c|c|c|c|c|}
\hline & \multicolumn{8}{|c|}{ Категории земель в 2015 г./Land categories in 2015} \\
\hline & & 1 & 2 & 3 & 4 & 5 & 6 & 7 & 8 \\
\hline \multirow{8}{*}{ 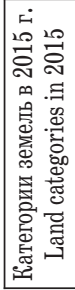 } & & 0,8443 & 0 & 0,0270 & 0,0593 & 0 & 0,063 & 0,0064 & 0 \\
\hline & 2 & 0 & 0,6452 & 0,0373 & 0,0125 & 0,0137 & 0,2566 & 0,0347 & 0 \\
\hline & 3 & 0 & 0 & 0,8482 & 0 & 0 & 0 & 0,0663 & 0,0855 \\
\hline & 4 & 0,0278 & 0,0036 & 0,0162 & 0,8131 & 0,0613 & 0,0129 & 0,0651 & 0 \\
\hline & & 0 & 0 & 0 & 0,2315 & 0,7685 & 0 & 0 & 0 \\
\hline & & 0,0140 & 0,0010 & 0,0235 & 0,0682 & 0 & 0,8132 & 0,0800 & 0 \\
\hline & & 0,0214 & 0,0214 & 0,0214 & 0,0214 & 0,0214 & 0,0214 & 0,8500 & 0,0214 \\
\hline & 8 & 0 & 0 & 0 & 0,1613 & 0,5299 & 0 & \begin{tabular}{|l|}
0 \\
\end{tabular} & 0,3088 \\
\hline
\end{tabular}

Примечание. Цифрами обозначены следующие земельные угодья: 1 - земли водного фонда; 2 - земли для сельскохозяйственных культур; 3 - земли для жилищного строительства; 4 - землли для рыбоводства; 5 - земли лесного фонда; 6 - рисовые поля; 7 - земли специального назначения; 8 - земли неиспользуемые.

Note. The numbers denote the following land use: 1 - land with rivers, streams, canals, springs and special-use water surface; 2 - land for cultivation of annual crops; 3 - residential land; 4 - land for aquaculture; 5 - forests; 6 - paddy land; 7 - special purpose lands; 8 - unused land.

В результате расчетов, проведенных по аналитической иерархической процедуре, получили нормированный вектор относительной важности факторов трансформации при оценке уровня ре-

таблица 3. Нормированный вектор относительной важности факторов трансформации при оценке ресурсного потенциала земель для разных видов их использования

Table 3. Normalized vector of relative importance of transformation factors in assessing resource potential of a territory for different types of land use

\begin{tabular}{|c|c|c|c|c|c|}
\hline Факторы/Factors & 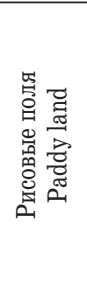 & 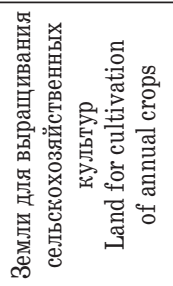 & 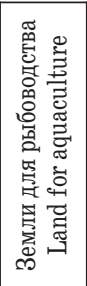 & 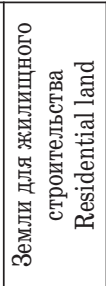 & 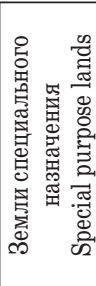 \\
\hline Тип почвы/Soil type & 0,1708 & 0,1483 & 0,0192 & - & - \\
\hline $\mathrm{pH}_{\mathrm{KCl}}$ & 0,1708 & 0,0645 & 0,1739 & - & - \\
\hline Гумусность/Humus & 0,0808 & 0,1483 & 0,0101 & - & - \\
\hline Степень насыщенности почвы основаниями/Degree of base saturation & 0,0643 & 0,0708 & 0,2581 & - & - \\
\hline Емкость катионного обмена CEC/Cation exchange capacity CEC & 0,1708 & 0,1386 & 0,0101 & - & - \\
\hline Содержание растворенных солей в почве/Soil salinity & 0,0808 & 0,0645 & 0,1014 & - & - \\
\hline Уровни увлажнения/Waterlogged levels & 0,0404 & 0,0645 & 0,1034 & - & - \\
\hline Гранулометрический состав/Granulometric soil structure & 0,0808 & 0,1483 & 0,0177 & - & - \\
\hline Система орошения/Irrigation systems & 0,0404 & 0,0645 & 0,1014 & - & - \\
\hline Слой глеев/Gleysol & 0,0190 & 0,0176 & 0,0514 & - & - \\
\hline Загрязнение почвы/Soil contamination & 0,0190 & 0,0176 & 0,0514 & - & - \\
\hline Эффективность экономики/Efficiency of economy & 0,0404 & 0,0320 & 0,0514 & - & - \\
\hline Уровень экономического развития коммун/Level of economic development of communes & - & - & - & 0,3596 & 0,2798 \\
\hline Плотность населения/Population density & 0,0109 & 0,0103 & 0,0253 & 0,1729 & 0,1247 \\
\hline Транспортное сообщения/Traffic system & 0,0109 & 0,0103 & 0,0253 & 0,1729 & 0,1247 \\
\hline Инфраструктура населения/Public infrastructure & - & - & - & 0,0293 & 0,2798 \\
\hline $\begin{array}{l}\text { Пригодность земли для выращивания сельскохозяйственных культур } \\
\text { Land suitability for cultivation of annual crops }\end{array}$ & - & - & - & 0,0663 & 0,0477 \\
\hline Пригодность земли для рисовых полей/Land suitability for paddy land & - & - & - & 0,0663 & 0,0477 \\
\hline Пригодность земли для рыбоводства/Land suitability for aquaculture & - & - & - & 0,0663 & 0,0477 \\
\hline Пригодность неиспользуемых земель/Unused land suitability & - & - & - & 0,0663 & 0,0477 \\
\hline Итого/Total & 1 & 1 & 1 & 1 & 1 \\
\hline
\end{tabular}


сурсного потенциала земель для разных видов их использования (табл. 3).

Анализ расчетов показал, что наиболее влиятельными при оценке уровня ресурсного потенциала земель рисовых полей являются такие факторы, как тип почвы, кислотность $\left(\mathrm{pH}_{\mathrm{Kcl}}\right)$, емкость катионного обмена. Факторы плотность населения и транспортное сообщение не оказывают существенного влияния на уровень ресурсного потенциала земель рисовых полей, поскольку в нормированном векторе относительной важности имеют минимальные значения.

Наибольшие значения относительной важности при оценке уровня ресурсного потенциала земель для выращивания других сельскохозяйственных культур имеют факторы: тип почвы, содержание гумуса и гранулометрический состав. Факторы плотность населения и транспортное сообщение не оказывают существенного влияния на уровень ре- сурсного потенциала полей сельскохозяйственных культур, поэтому в нормированном векторе относительной важности имеют минимальные значения.

Уровень ресурсного потенциала земель для рыбоводства в первую очередь зависит от таких факторов, как: степень насыщенности почвы основаниями, кислотность, уровень увлажнения и содержание растворенных солей в почве. Менее влиятельными при оценке ресурсного потенциала земель для рыбоводства следует считать почвенные факторы: тип почвы, содержание гумуса, гранулометрический состав и емкость катионного обмена.

Для земель жилищного строительства наибольшие значения в нормированном векторе относительной важности имеют факторы: плотность населения, транспортное сообщение, инфраструктура населения. Менее влиятельными при оценке ресурсного потенциала земель этой категории можно считать фактор уровня экономического развития коммун.

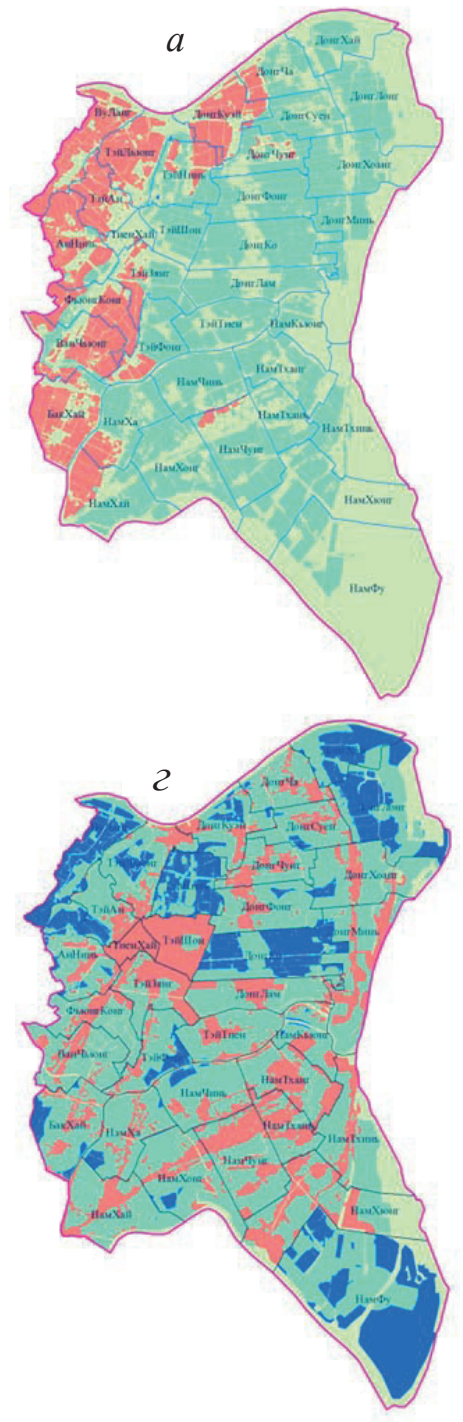

1

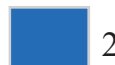

2 3
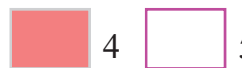

5

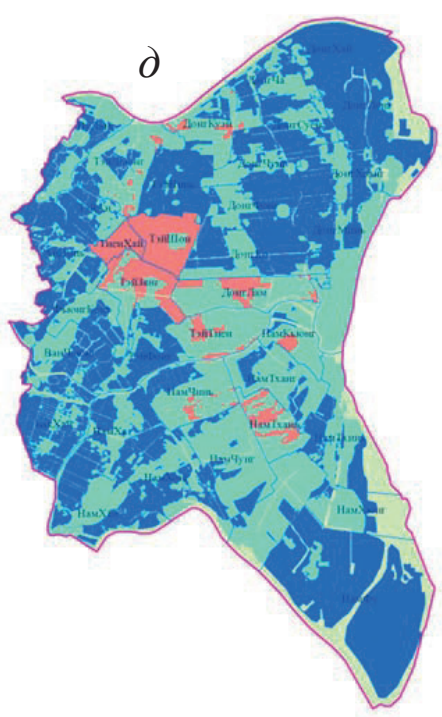

Pис.1. Схематические карты пригодности земель для разных видов использования района Тиенхая: а) рисовые поля; б) сельскохозяйственные культуры; в) рыбоводство; г) жилищное строительство; д) спеииальное назначение. Условные обозначения: 1 - класс временно непригодных земель; 2 - класс земель ограниченной пригодности; 3 - класс земель средней пригодности; 4 - класс земель высокой пригодности; 5 - граница района; 6 - граница коммуны

Fig. 1. Land use maps in Tienhai district for: a) paddy land; б) cultivation of annual crops; в) aquaculture; 2) residential land; d) special purposes land. Legend: 1 - currently not suitable; 2 - marginally suitable; 3 - moderately suitable; 4 - highly suitable; 5 - border of the district; 6 - border of the commune 
Таблица 4. Значения уровня ресурсного потенциала зелель района Тиенхая для разных видов использования

Table 4. Values of Tienhai district resource potential level for different types of land use

\begin{tabular}{|c|c|c|c|c|c|c|c|c|}
\hline \multirow{3}{*}{$\begin{array}{c}\text { Виды земельных угодий } \\
\text { Types of land use }\end{array}$} & \multicolumn{8}{|c|}{ Баллы уровней пригодности земель/Land use level score } \\
\hline & \multicolumn{2}{|c|}{$\begin{array}{c}\text { Bременно непригодные } \\
\text { Currently not suitable }\end{array}$} & \multicolumn{2}{|c|}{$\begin{array}{c}\text { Ограниченно пригодные } \\
\text { Marginally suitable }\end{array}$} & \multicolumn{2}{|c|}{$\begin{array}{l}\text { Средне пригодные } \\
\text { Moderately suitable }\end{array}$} & \multicolumn{2}{|c|}{$\begin{array}{c}\text { Высоко пригодные } \\
\text { Highly suitable }\end{array}$} \\
\hline & \begin{tabular}{|c|} 
Площадь, га \\
Area, ha
\end{tabular} & $\begin{array}{c}\text { Доля } \\
\text { Part, \% }\end{array}$ & \begin{tabular}{|c|} 
Площадь, га \\
Area, ha
\end{tabular} & $\begin{array}{c}\text { Доля } \\
\text { Part, \% }\end{array}$ & $\begin{array}{c}\text { Площадь, га } \\
\text { Area, ha }\end{array}$ & $\begin{array}{c}\text { Доля } \\
\text { Part, \% }\end{array}$ & $\begin{array}{c}\text { Площадь, га } \\
\text { Area, ha }\end{array}$ & $\begin{array}{c}\text { Доля } \\
\text { Part, } \%\end{array}$ \\
\hline Земли рисовых полей/Paddy land & 11493,32 & 48,93 & 2,14 & 0,01 & 8455,76 & 36,00 & 3536,64 & 15,06 \\
\hline $\begin{array}{l}\text { Земли для выращивания } \\
\text { сельскохозяйственных культур } \\
\text { Land for cultivation of annual crops }\end{array}$ & 11493,32 & 48,93 & 596,02 & 2,54 & 9843,72 & 41,91 & 1554,8 & 6,62 \\
\hline $\begin{array}{l}\text { Земли для рыбоводства } \\
\text { Land for aquaculture }\end{array}$ & 11491,32 & 48,93 & 0,00 & 0,00 & 7856,14 & 33,44 & 4140,4 & 17,63 \\
\hline $\begin{array}{l}\text { Земли для жилищного строительства } \\
\text { Residential land }\end{array}$ & 2226,41 & 9,48 & 3862,73 & 16,45 & 12241,43 & 52,12 & 5157,29 & 21,96 \\
\hline $\begin{array}{l}\text { Земли специального назначения } \\
\text { Special purpose land }\end{array}$ & 2226,41 & 9,48 & 10290,93 & 43,81 & 9646,39 & 41,07 & 1324,13 & 5,64 \\
\hline
\end{tabular}

На уровень ресурсного потенциала земель специального назначения значительное влияние оказывают факторы: плотность населения, уровень экономического развития коммун, транспортное сообщение, инфраструктура поселения. Менее влиятельными при оценке ресурсного потенциала земель специального назначения следует считать факторы сельскохозяйственных и неиспользуемых земель.

По исходным данным и формуле (6) с помощью программ АгсGis и Idrisi Selva рассчитали значения уровней ресурсного потенциала земель Тиенхая для разных видов использования (табл. 4) и разработали карты пригодности их для каждого типа земельных угодий этого региона (рис. 1).

По разработанным нами картам по программам АгсGis и Idrisi Selva рассчитаны площади земель различных видов их использования.

Площадь высокой пригодности земель для рисовых полей занимает 3536,64 га (15,06 \% ), которые находятся на западе района исследований. Площади временно непригодных и средней пригодности земель являются преобладающими в районе Тиенхая и соответственно составляют 1493,32 га $(48,93 \%$ ) и 8455,76 га $(36,00 \%)$. Площадь ограниченной пригодности земель является незначительной $-2,14$ га $(0,01 \%)$.

Высокая пригодность земель для выращивания сельскохозяйственных культур занимает площадь 1554,8 га $(6,62 \%)$. Эти земли находятся на юго-западной и северной части района исследований. Временно непригодные и средней пригодности земли являются преобладающими в районе Тиенхая и составляют соответственно площадь 11493,32 га $(48,93 \%)$ и 9843,72 га (41,91 \%). Площадь ограниченной пригодности земель составляет 596,02 га (2,54 \%).

Временно непригодные и средней пригодности земли для рыбоводства занимают соответственно площадь 11493,32 га $(48,93 \%)$ и 7856,14 га $(33,44 \%)$. Земли высокой пригодности располагаются на западе района исследований и занимают площадь 4140,4 га (17,63\%).

Земли высокой пригодности для жилищного строительства занимают площадь 5157,29 га $(21,96 \%)$ и встречаются во всех сельскохозяйственных коммунах района Тиенхая. В регионе преобладают земли средней пригодности, которые занимают площадь 12241,43 га $(52,12 \%)$. Bременно непригодные и ограниченной пригодности земли занимают соответственно 2226,41 га $(9,48 \%)$ и 3862,73 га $(16,45 \%)$.

В центре района исследований располагаются земли высокой пригодности для специального назначения, которые занимают площадь 1324,13 га $(5,64 \%)$. В районе исследований преобладают земли ограниченной и средней пригодности, которые занимают соответственно площадь 10290,93 га, $(43,81 \%)$ и 9646,39 га $(41,07 \%)$. Временно непригодные земли занимают оставшуюся часть района - 2226,41 га, $(9,48 \%)$.

Используя матрицу структуру земельных угодий в 2015 г. и карты пригодности земель для каждого типа земельных угодий в районе Тиенхая нами составлен прогноз трансформации земельных ресурсов на 10 лет. Для прогноза использован «модуль CA Markov», представленный в ГИС-технологии Idrisi Selva [28]. Заметим также, что параметры «модуля CA_Markov» задавались по умолчанию, а размер анализируемой окрестности КА быль аналогичен размеру $5 \times 5$ [29]. По построенной модели к 2025 г. будут следующие структуры земельных угодий (рис. 2 , табл. 5).

Площадь земель для выращивания сельскохозяйственных культур в 2015 г. занимала 870,91 га $(3,7 \%)$, а к 2025 г. они составят 620,19 га $(2,64 \%)$, то есть произойдет уменьшение площади на 250,72 га $(28,79 \%)$. В то же время земли специального назначения в 2015 г. составляли 579,1 га $(2,5 \%)$, а к 2025 г. увеличатся до 1889,19 га (8,04 \%), то есть произойдет увеличение площади данного типа земельного угодья на 1310,09 га $(226,23$ \% ). Рисовые поля в 2015 г. составляли 11859,40 га $(50,5 \%)$, а к 2025 г. займут площадь 10079,96 га $(42,92 \%)$, что свидетельствует об уменьшении площади на 1779,44 га $(15,00 \%)$. Земли для жилищного строительства в 2015 г. занимали площадь 4468,25 га (19,00\%), а к 2025 г. - 4486,18 (19,10 \%), что свидетельствует об увеличении площади на 17,93 га $(0,40 \%)$. Земли лесного, водного фондов и для рыбоводства в 2015 г. составляли соответственно 875,22 га 

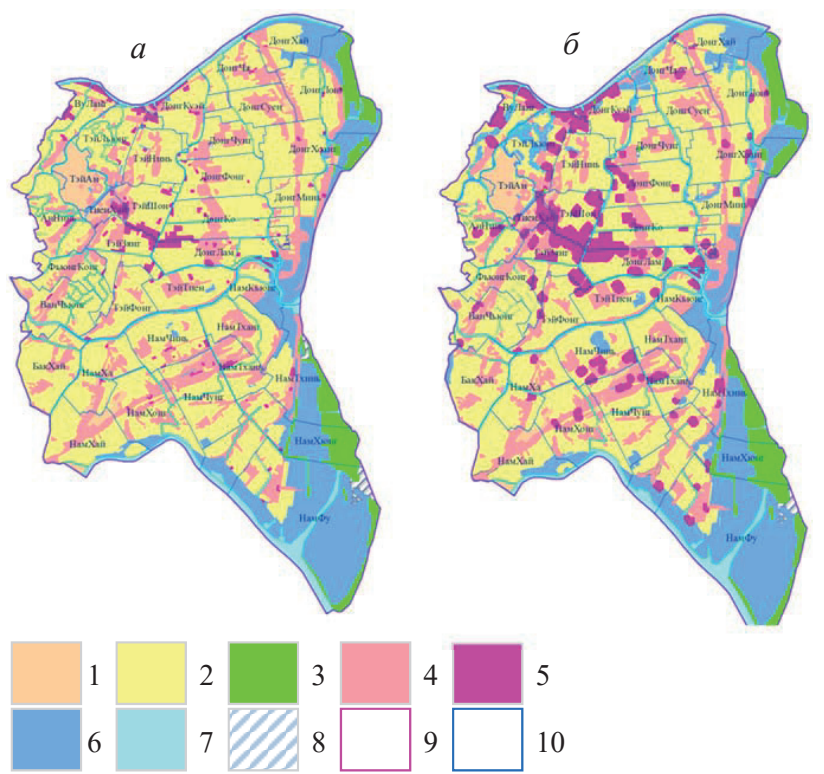

Pис. 2. Карты структуры земельных угодий в Тиенхае в 2015 г. (а) и прогноза их структуры к 2025 г. (б). Условные обозначения: 1 земли для выращивания сельскохозяйственных культур; 2 - рисовые поля; 3 - зелли лесного фонда; 4 - земли для жилищного строительства; 5 - зелли специального назначения; 6 - зелли для рыбоводства; 7 - земли водного фонда; 8 - неиспользуемые земли; 9 - граница района; 10 - граница комлунь

Fig. 2. Maps of land structure in Tienhai in 2015 (a) and forecast of their structure by 2025 ( $\sigma$ ). Legend: 1 - land for cultivation of annual crops; 2 - paddy land; 3 - forests; 4 - residential land; 5 - special purpose land; 6 - land for aquaculture; 7 - land with rivers, streams, canals, springs and special-use water surface; 8 - unused land; 9 - border of the district; 10 - border of the commune

Таблища 5. Динамика трансформации земельного фонда Тиенхая по категориял зелель к 2025 2.

Table 5. Dynamics of transformation of the Tienhai land fund by land category by 2025

\begin{tabular}{|c|c|c|c|c|}
\hline \multirow{2}{*}{$\begin{array}{l}\text { Виды земельных угодий } \\
\text { Type of land use }\end{array}$} & \multicolumn{2}{|c|}{2015 г. } & \multicolumn{2}{|c|}{2025 г. } \\
\hline & га & $\%$ & га & $\%$ \\
\hline $\begin{array}{l}\text { Земли для выращивания сель- } \\
\text { скохозяйственных культур } \\
\text { Land for cultivation of annual } \\
\text { crops }\end{array}$ & 870,91 & 3,7 & 620,19 & 2,64 \\
\hline $\begin{array}{l}\text { Земли неиспользуемые } \\
\text { Unused land }\end{array}$ & 87,56 & 0,4 & 67,00 & 0,29 \\
\hline $\begin{array}{l}\text { Земли специального назначения } \\
\text { Special purpose land }\end{array}$ & 579,10 & 2,5 & 1889,19 & 8,04 \\
\hline $\begin{array}{l}\text { Земли рисовых полей } \\
\text { Paddy land }\end{array}$ & 11859,40 & 50,5 & 10079,96 & 42,92 \\
\hline $\begin{array}{l}\text { Земли для жилищного } \\
\text { строительства } \\
\text { Residential land }\end{array}$ & 4468,25 & 19,00 & 4486,18 & 19,10 \\
\hline $\begin{array}{l}\text { Земли лесного фонда } \\
\text { Land for forests }\end{array}$ & 875,22 & 3,7 & 1077,69 & 4,59 \\
\hline $\begin{array}{l}\text { Земли водного фонда } \\
\text { Land with rivers, streams, } \\
\text { canals, springs and special-use } \\
\text { water surface }\end{array}$ & 1275,73 & 5,4 & 1357,42 & 5,78 \\
\hline $\begin{array}{l}\text { Земли для рыбаводства } \\
\text { Land for aquaculture }\end{array}$ & 3471,69 & 14,8 & 3910,23 & 16,65 \\
\hline Итого & 23487,86 & 100,00 & 23487,86 & 100,00 \\
\hline
\end{tabular}

$(3,7 \%), 1275,73(5,4 \%)$ и 3471,69 га $(14,8 \%)$. Через 10 лет земли этих категорий займут площадь соответственно 1077,69 га $(4,59 \%), 1357,42$ га $(5,78 \%$ ) и 3910,23 га $(16,65 \%)$. По прогнозу можно сказать, что их площадь увеличится соответственно на 202,47 га $(23,13 \%), 81,69$ га $(6,40 \%$ ) и 438,54 га $(12,63 \%)$. Неиспользуемые земли в
2015 г. занимали площадь 87,56 га $(0,40 \%)$, а к 2025 г. по данным прогнозной карты составят 67,0 га $(0,29 \%)$, то есть площадь земель этой категории уменьшится на 20,56 га (23,48 \%).

\section{Заключение}

Результаты исследований земельных ресурсов в районе Тиенхая Вьетнама позволили выявить виды угодий и землепользований, оценить их ресурсный потенциал. Выявлены основные тенденции трансформации земель по прогнозу с 2015 по 2025 гг. Установлено уменьшение площади земель для выращивания сельскохозяйственных культур $(28,79 \%)$, рисовых полей на $(15,00 \%)$ и неиспользуемые земли на $(23,48$ \% ). Уменьшение площади этих видов земельных угодий объясняется тем, что они имеют ограниченную пригодность и низкую экономическую эффективность, что привело к переводу их в другие категории. Площади земель лесного, водного фонда, рыбоводства, жилищного строительства и специального назначения увеличились соответственно на 23,$13 ; 6,40$; 12,$63 ; 0,40$ и $226,23 \%$. Увеличение площади этих видов земельных угодий объясняется строительством горных предприятий и жилья для работников на землях сельскохозяйственных культур, рисовых полей и неиспользуемых ранее территориях. Кроме того, территория Тиенхай представляет прибрежную равнину, поэтому земли обладают высоким потенциалом для развития рыбоводства, выращивания мангровых лесов и расширения водных ресурсов, поэтому площадь этих видов земельных угодий значительно увеличилась. 
Таким образом, при оценке трансформации землепользований в районе Тиенхая подтвердились данные, полученные на модельных изображениях [30]. Полученные данные показали основные тенденции трансформации землепользований на изучаемой территории. По уровню пригодности земель, вероятностной информации об изменениях земельных угодий,

\section{СПИСОК ЛИТЕРАТУРЫ}

1. Ковязин В.Ф., Нгуен Т.С., Романчиков А.Ю. Трансформация землепользования в зоне бокситового рудника танрай республики Вьетнам // Известия ТулГу. Науки о Земле. - 2017. Вып. 4. - С. 28-39.

2. Ковязин В.Ф., Нгуен Т.С., Боголюбова А.А. Трансформация землепользований на Севере и юге Вьетнама // Вестник Московского государственного областного университета. Серия: Естественные науки. - 2017. - № 4. - С. 95-110.

3. Pham T.T.H. Applying a Systematic Review to Land Use Land Cover Change in Northern Upland Vietnam: the Missing Case of the Borderlands // Geogr. Res. - 2015. - T. 53 (4). - P. 419-435.

4. Rawat J.S. Monitoring land use/cover change using remote sensing and geographic information systems techniques: a case study of Hawalbagh block, district Almora, Uttarakhand, India // Egypt. J. Remote Sens. Sp. Sci. - 2015. - V. 18. - № 1. - P. 77-84.

5. A Framework for land evaluation. Table of contents // Soil Bulletin 32. Soil resources development and conservation service land andwater development division FA0. And agriculture organization of theunited nations. Rome, 1976. - 66 p. URL: https://www.mpl.ird.fr/crea/taller-colombia/FA0/AGLL/pdfdocs/framele.pdf (дата обращения 10.02.2019).

6. Ковязин В.Ф., Нгуен Т.С., Демидова П.М. Влияние изменений законодательства Вьетнама на мониторинг и пользование земельными ресурсами // Астраханский вестник экологического образования. - 2018. - № 2. - С. 89-94.

7. Luong D.T. Soil characteristics and limited factors of arable land in Northwest Vietnam / Vietnam Academy of Agriculture Sciences. Hanoi. - 2016. - № 2. - P. 1031-1042.

8. Tran V.T. Input of Climate Change on Coastal Ecosystems in Thai Binh Province and Response Capacity // VNU Science Journal. 2016. - V. 32. - P. 392-399.

9. Ministry of Agriculture and Rural Development of the socialist republic of Vietnam. National Standard 8409: 2010. Process of evaluating agricultural production land to establish district-level land use planning. - Vietnam, 2010. - $14 \mathrm{p}$.

10. Le Q.T. Identification of criterions for sub-quantitative land evaluation in two different ecosystem zones // Scientific journal of Cantho University. - 2010. - V. 15b. - P. 114-124.

11. Ministry of Agriculture and Rural Development of the socialist republic of Vietnam. Answer - Criteria for evaluating agricultural land for land use planning at district level. - Hanoi, 2010. - 63 p.

12. Provincial Department of Natural Resources and Environment ThaiBinh. Report on the current state of land use in the province of ThaiBinh in 2014. - ThaiBinh, 2015. - $35 \mathrm{p}$.

13. ThaiBinh statstical yearbook 2016. - ThaiBinh: ThaiBinh statistic office, 2017. $-428 \mathrm{p}$.

14. Tran A.T. Application of MarKov and Cellular Automata models in the study of land surface change forecast // VNU University of Science. - Hanoi, 2011. - 70 p. текущего состояния земель и наличия специальной программы ГИС-технологии можно прогнозировать тенденцию трансформации земель на перспективу. Прогнозные данные о земельных угодьях можно использовать для планирования хозяйственных мероприятий и грамотного управления земельными ресурсами социалистической республики Вьетнам.

15. Nguyen T.H.T. Socio-economic effects of agricultural land conversion for urbandevelopment: Case study of Hanoi, Vietnam // Land use policy. - 2016. - V. 54. - P. 583-592.

16. Nguyen V.S. Agricultural land conversion and its effects on farmers in contemporary Vietnam // Focaal. - 2009. - Iss. 54. P. 106-113.

17. Dang H.V. The tragedy of land transfer. URL: http://vietnamnet.vn/vn/thoi-su/bi-kich-trong-chuyen-dich-dat-dai41372.html (дата обращения 01.02.2019).

18. Le Q.T. Assessment of land. - Cantho: CanTho University Publ., 1997. $-80 \mathrm{p}$.

19. Can T.V., Nguyen T.S. Selection Method for Calculating Weights to Determine Flood vulnerability index in VuGia-ThuBon basin // VNU Science Journal. - 2015. - V. 31. - № 1S. - P. 93-102.

20. Saaty Th.L. Decision making with the analytic hierarchy process // Int. J. Services Sciences. - 2008. - V. 1. - P. 83-98.

21. Замятин Н.Г., Марков А.В. Подход к моделированию изменений земной поверхности с использованием клеточных автоматов // Иввестия Томского политехнического университета. 2005. - T. 308. - № 6. - C. 164-169.

22. Ковязин В.Ф., Нгуен Т.С., Романчиков А.Ю. Использование цепи Маркова для прогнозирования состояния землепользования в будущем в коммуне КуангЧюк провинции Дакнонг Вьетнама // Сборник трудов. - Симферополь: ПолИПРИНТ, 2018. - C. 321-324.

23. Теория случайных процессов. Ч. 2. Марковские процессы. Томск. Томский политехнический университет, 2014. - 58 с.

24. Alireza Ildoromi, Mahtab Safari Shad. Land Use Change Prediction using a Hybrid (CA-Markov) Model // ECOPERSIA. 2017. - V. 5 (1). - P. 1631-1640.

25. Лурье И.К. Основы геоинформатики и создание ГИС. - М.: ИНЭКС-92, 2002. - 140 c.

26. Guindon B., Zhang Y., Dillabaugh C. Landsat Urban Mapping Based on a Combined Spectral-Spatial Methodology // Remote Sensing of Environment. - Canada. 2004. - V. 92. - № 2. - P. 218-232.

27. Getting Started With ArcGIS. Available at: http://downloads.esri.com/support/documentation/ao_/1003Getting_Started with_ArcGIS.pdf (accessed 2 February 2019). Интернет-ресурс.

28. Predicting Urban Land Use Changes Using a CA-Markov Model / J. Nouri, A. Gharagozlou, R. Arjmandi, Sh. Faryadi, Adl. Mahsa // Arabian Journal for Science and Engineering. 2014. URL: https://www.researchgate.net/publication/271913588_Predicting_Urban_Land_Use_Changes_Using_a_CA-Markov_Model

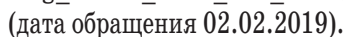

29. Eastman J.R. IDRISI Selva Tutorial. - USA: IDRISI Production, Clark University, 2012. - $354 \mathrm{p}$.

30. Gillespie, J. Vietnam: will property rights solve land disputes.Available at: http://www.eastasiaforum.org/2012/05/22/vietnam-will-property-rights-solve-land-disputes/.(дата обращения 02.02.2019).

Поступила 12.02.2019 2.

\section{Информация об авторах}

Ковязин В.Ф., доктор биологических наук, профессор кафедры инженерной геодезии Санкт-Петербургского горного университета.

Нгуен Тхи Суан, аспирантка кафедры инженерной геодезии Санкт-Петербургского горного университета. 
UDC 332.334

\title{
DEVELOPMENT OF PREDICTIVE MODELS OF LAND USE CHANGE IN VIETNAM
}

\author{
Vasily F. Kovyazin', \\ vfkedr@mail.ru \\ Thi Xuan Nguyen', \\ ntxuandc81@gmail.com \\ 1 Saint-Petersburg Mining university, \\ 2, 213t Line, Vasilievsly Island, St. Petersburg, 199106, Russia.
}

The relevance. Vietnam is an agricultural country, but at present its development is following the path of industrialization, and the government remained concerned about the quantity and quality of agricultural land. Therefore, assessing the resource potential of different land uses and forecasting land-use trends in Vietnam play a key role in the country's land management. The resource potential of lands was studied for the administrative area of Tienhai district, which is a coastal region of the country, where the agricultural sector of the economy prevails and many types of land use are typical.

The main aim of the research is to assess land suitability for different types of land use for predicting the trend of their use in the future.

Object of the researches is the state land of Tienhai district in the Socialist Republic of Vietnam.

Methods: methods of empirical level: description, observation, measurement, comparison, questioning, generalization and modeling. To identify the dynamics of land plots of different categories the authors have used the method of satellite images, and for their processing - GIS-technology. FAO (food and agriculture organization of the United Nations) and peer review methods were applied to assess land suitability for different land uses. The value of land transformation coefficients for different types of land use is calculated by the method of analytical hierarchical Saaty procedure. Markov chains and modern computer programs and technologies were used to develop a predictive model of land use transformation in Vietnam.

Results. Based on the interpretation of satellite images of the territory and GIS technologies the authors plotted the matrix of land transformation probability in Tienhai from 2005 to 2015. The normalized vector of relative importance of the transformation factors when assessing resource potentials of the territory for different types of land use according to the method of analytical hierarchy Saaty procedure was formed with the help of experts. The authors designed the schematic maps of land suitability for different types of land and predicted the areas of land use within the studied region in 10 years.

\section{Key words:}

Land use, transformation matrix, predictive model, Markov chain, land suitability.

\section{REFERENCES}

1. Kovyazin V.F., Nguyen T.S., Romanchikov A.Yu. Land use transformation in the Tanrai region, Vietnam. Proceedings of the TSU. Earth Sciences, 2017, Iss. 4, pp. 28-39. In Rus.

2. Kovyazin V.F, Nguyen T.S., Bogolyubova A.A. Land use transformation in the north and the south of Vietnam. Bulletin of the Moscow Region State University. Series: Natural Sciences, 2017, no. 4, pp. 95-110. In Rus.

3. Pham T.T.H. Applying a Systematic Review to Land Use Land Cover Change in Northern Upland Vietnam: the Missing Case of the Borderlands. Geogr. Res., 2015, vol. 53 (4), pp. 419-435.

4. Rawat J.S. Monitoring land use/cover change using remote sensing and geographic information systems techniques: a case study of Hawalbagh block, district Almora, Uttarakhand, India. Egypt. J. Remote Sens. Sp. Sci., 2015, vol. 18, no. 1, pp. 77-84.

5. A Framework for land evaluation. Table of contents. Soil Bulletin 32. Soil resources development and conservation service land andwater development division FAO. And agriculture organization of theunited nations. Rome, 1976. 66 p. Available ast: https://www.mpl.ird.fr/crea/taller-colombia/FA0/AGLL/pdfdocs/framele.pdf (accessed 10 February 2019).

6. Kovyazin V.F., Nguyen T.S., Demidova P.M. The impact of changes in the legislation of Vietnam on monitoring and using of land resources. Astrakhan Bulletin for Environmental Education, 2018, no. 2, pp. 89-94. In Rus.

7. Luong D.T. Soil characteristics and limited factors of arable land in Northwest Vietnam. Vietnam Academy of Agriculture Sciences. Hanoi. 2016, no. 2, pp. 1031-1042.
8. Tran V.T. Input of Climate Change on Coastal Ecosystems in Thai Binh Province and Response Capacity. VNU Science Journal, Hanoi, 2016, vol. 32, pp. 392-399.

9. Ministry of Agriculture and Rural Development of the socialist republic of Vietnam. National Standard 8409: 2010. Process of evaluating agricultural production land to establish district-level land use planning. Vietnam, 2010.14 p.

10. Le Q.T. Identification of criterions for sub-quantitative land evaluation in two different ecosystem zones. Scientific journal of Cantho University, 2010, vol. 15b, pp. 114-124.

11. Ministry of Agriculture and Rural Development of the socialist republic of Vietnam. Answer. Criteria for evaluating agricultural land for land use planning at district level. Hanoi, 2010.63 p.

12. Provincial Department of Natural Resources and Environment ThaiBinh. Report on the current state of land use in the province of ThaiBinh in 2014. ThaiBinh, 2015. $35 \mathrm{p}$.

13. ThaiBinh statstical yearbook 2016. ThaiBinh, ThaiBinh statistic office, 2017. $428 \mathrm{p}$.

14. Tran A.T. Application of MarKov and Cellular Automata models in the study of land surface change forecast. VNU University of Science. Hanoi, 2011. 70 p.

15. Nguyen T.H.T. Socio-economic effects of agricultural land conversion for urbandevelopment: Case study of Hanoi, Vietnam. Land use policy, 2016, vol. 54, pp. 583-592.

16. Nguyen V.S. Agricultural land conversion and its effects on farmers in contemporary Vietnam. Focaal, 2009, Iss. 54, pp. 106-113.

17. Dang H.V. The tragedy of land transfer. Available at: http://vietnamnet.vn/vn/thoi-su/bi-kich-trong-chuyen-dich-dat-dai41372.html (accessed 1 February 2019). 
18. Le Q.T. Assessment of land. Cantho, CanTho University Pub.l, $1997.80 \mathrm{p}$.

19. Can T.V., Nguyen T.S. Selection Method for Calculating Weights to Determine Flood Vulnerability Index in VuGia-ThuBon basin. VNU Science Journal, 2015, vol. 31, no. 1S, pp. 93-102.

20. Saaty Th.L. Saaty Th.L. Decision making with the analytic hierarchy process. Int. J. Services Sciences, 2008, vol. 1, pp. 83-98.

21. Zamyatin N.G., Markov A.V. Approach to modeling changes in the earth's surface using cellular automata. Bulletin of the Tomsk Polytechnic University, 2005, vol. 308, no. 6, pp. 164-169.

22. Kovyazin V.F., Nguyen T.S., Romanchikov A.Yu. Ispolzovaniya tsepi Markova dlya prognozirovaniya sostoyaniya zemlepolzovaniya v budushchem v kommune KuangChyuk provintsii Daknong Vyetnama [The use of the Markov chain to predict the state of land use in the future in the Quangtruc commune, Daknong Province, Vietnam]. Sbornik trudov. Simferopol, POLIPRINT Publ., 2018. pp. 321-324.

23. Teoriya sluchaynykh protsessov. Ch. 2. Markovskie protsessy [Theory of random processes. P. 2. Markov processes]. Tomsk, Tomsk Polytechnic University Publ. house, 2014. 58 p.

24. Alireza Ildoromi, Mahtab Safari Shad. Land Use Change Prediction using a Hybrid (CA-Markov) Model. ECOPERSIA. 2017, vol. 5 (1), pp. 1631-1640.
25. Lurye I.K. Osnovy geoinformatiki i sozdaniye GIS [Basics of geoinformatics and the creation of GIS]. Moscow, INEKS, 2002. $140 \mathrm{p}$.

26. Guindon B., Zhang Y., Dillabaugh C. Landsat Urban Mapping Based on a Combined Spectral-Spatial Methodology. Remote Sensing of Environment. Canada, 2004, vol. 92, no. 2, pp. 218-232.

27. Getting Started with ArcGIS. Available at: http://downloads.esri.com/support/documentation/ao_/1003Getting_Started_with_ArcGIS.pdf (accessed 2 February 2019).

28. Nouri J., Gharagozlou A., Arjmandi R., Faryadi Sh., Mahsa Adl. Predicting Urban Land Use Changes Using a CA-Markov Model. Arabian Journal for Science and Engineering, 2014. Available at: https://www.researchgate.net/publication/271913588_Predicting_Urban_Land_Use_Changes_Using_a_CA-Markov_Model (accessed 2 February 2019).

29. Eastman J.R. IDRISI Selva Tutorial. USA, IDRISI Production, Clark University, 2012. 354 p.

30. Gillespie J. Vietnam: will property rights solve land disputes. Available at: http://www.eastasiaforum.org/2012/05/22/vietnam-will-property-rights-solve-land-disputes/ (accessed 2 February 2019).

Received: 12 February 2019.

\section{Information about the authors}

Vasily F. Kovyazin, Dr. Sc., professor, Saint-Petersburg Mining university.

Thi Xuan Nguyen, postgraduate, Saint-Petersburg Mining university. 